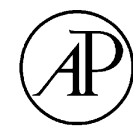

ACADEMIC

PRESS

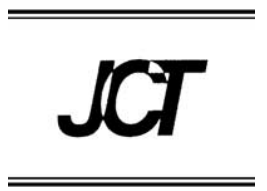

www.elsevier.com/locate/jct

\title{
Enthalpy of vaporisation of butanediol isomers
}

\author{
M. Ermelinda Eusébio *, A.J. Lopes Jesus, Mafalda S.C. Cruz, \\ M. Luísa P. Leitão, J. Simões Redinha \\ Departamento de Química, Universidade de Coimbra, Coimbra 3049, Portugal \\ Received 31 July 2001; accepted 2 October 2002
}

\begin{abstract}
The enthalpies of vaporisation of isomers of butanediol were determined by calorimetric measurements. A Knudsen effusion cell was used for this purpose.

The values of the standard enthalpy of vaporisation obtained for the different isomers were compared and significant differences were found between them.
\end{abstract}

(c) 2003 Elsevier Science Ltd. All rights reserved.

Keywords: Butanediol isomers; Vaporisation enthalpy; Calorimetry

\section{Introduction}

The enthalpy of vaporisation is a property which is often used for determining other thermodynamic quantities and for investigating the structure of compounds in the liquid or gas phase. Indeed, the enthalpy of transferring a solute molecule from a gas to solution, the enthalpy of solvation, a very important property in solvation research when the solute is liquid, is usually determined from a thermodynamic cycle which includes the enthalpy of solvation, solution and vaporisation. Also, from the enthalpy of vaporisation the energy level (Hartree-Fock energy + zero point vibrational energy + temperature dependent vibrational, rotational and translational energies) of a certain compound in a gas or liquid phase can be characterised provided this quantity is known for one of these states. If we bear in mind that a liquid has a more complex structure compared to that of a gas, pro-

\footnotetext{
${ }^{*}$ Corresponding author. Fax: +351-39-827-703.

E-mail address: quierme@ci.uc.pt (M. Ermelinda Eusébio).
} 
TABLE 1

Values quoted in the literature for the enthalpy of vaporisation $\Delta_{\mathrm{vap}} H_{\mathrm{m}}^{0}$ of butanediols at $T=298.15 \mathrm{~K}$

\begin{tabular}{lll}
\hline Substance & $\Delta_{\mathrm{vap}} H_{\mathrm{m}}^{0}$ & Method \\
\cline { 2 - 2 } & $\mathrm{kJ} \cdot \mathrm{mol}^{-1}$ & \\
\hline$( \pm)-1,2-$-Butanediol & $71.6 \pm 0.8^{a} ; 69.1^{b}$ & Vapour pressure data \\
$( \pm)-1,3-$-Butanediol & $67.8 \pm 2.1^{c} ; 74.5 \pm 1.0^{a}$ & Vapour pressure data \\
1,4-Butanediol & $76.6 \pm 1.7^{c} ; 79.3 \pm 0.5^{d}$ & Vapour pressure data; Calorimetry \\
meso-Butanediol & $59.2^{e}$ & \\
\hline
\end{tabular}

${ }^{a}$ Ref. [1].

${ }^{b}$ Ref. [2].

${ }^{c}$ Ref. [3].

${ }^{d}$ Ref. [4].

${ }^{e}$ Ref. [5].

gress in the understanding of the liquid structure can be achieved via the knowledge of the enthalpy of vaporisation. As a characteristic property of a given substance the enthalpy of vaporisation can also give information on the structural or chemical purity of a liquid.

In the present work the enthalpies of vaporisation of butanediols are determined for all commercially available isomers and enantiomers. These compounds are part of an interesting class of compounds, with relatively short chains, a certain flexibility and the possibility of establishing hydrogen bonds. Different isomers and enantiomers exist but only a few experimental data on their enthalpy of vaporization are found in the literature. Table 1 contains values for the enthalpy of vaporisation of butanediol isomers reported by various workers. The discrepancies between the values of a given compound, the poor accuracy of some results or the lack of information on others lead to the indubitable conclusion that work should be done in order to get reliable results for these substances.

\section{Experimental}

The butanediols used in the present study were purchased from Aldrich Company and were of the best quality commercially available. The mass fraction purity was specified to be $x>0.99$ for all substances except for $R$-1,3-butanediol, $x>0.98$. The substances were used without further purification except for $R$-1,3-butanediol which was purified by sublimation by a cold finger technique. The purity was checked by gas-liquid chromatography using a polar column (DB-wax polyethyleneglycol) and a non-polar one (OV-1 polydimethylsyloxane). Values in the range $0.991 \leqslant x \leqslant 0.998$ were found for the mass fraction purity. The test substances were kept over molecular sieves in a dry atmosphere and manipulated inside a glove box filled with dry nitrogen.

The determination of the heat of vaporisation was carried out by calorimetry using a Knudsen effusion cell. A cylindrical vaporisation/sublimation cell with an internal diameter $\phi=10.9 \mathrm{~mm}$ and a height $h=10.2 \mathrm{~mm}$ was used. The effusion hole 
was bored in a teflon joint with thickness $l=0.2 \mathrm{~mm}$ placed over a viton joint in order to assure tightness. Different effusion hole diameters $\phi_{0}$ where used for the different compounds: $\phi_{0}=2 \mathrm{~mm}$ for 1,4-butanediol; $\phi_{0}=1 \mathrm{~mm}$ for $( \pm)-1,3$ - and $R$-1,3butanediols; $\phi_{0}=0.5 \mathrm{~mm}$ for $( \pm)-1,2$ and meso-2,3-butanediols; $\phi_{0}=0.2 \mathrm{~mm}$ for $(S, S)$-2,3-butanediol. The vaporization/sublimation cell containing an amount of substance between (10 and 25) $\mathrm{mg}$ was inserted into a cylindrical stainless steel tube adapted to the C-80 Setaram calorimeter cell compartment, which was connected to the vacuum line. An empty cell was used as reference. The vacuum system consisted of a two-stage Edwards E2M18 rotary pump and an Edwards EXT500CR turbomolecular pump. The vacuum attained was of the order of $10^{-4} \mathrm{~Pa}$. The device used for closing and opening the cells was based on that described by Sabbah [6]. The opening process did not contribute to the measured signal as verified in blank experiments.

The experiments were carried out under conditions leading to a total vaporisation of the substance in the cell. The time required for completing the vaporisation was two to five hours, corresponding to an effusion rate of the order of $v=\left(7 \cdot 10^{-10}\right) \mathrm{kg} \cdot \mathrm{s}^{-1}$ in the case of 1,4 -butanediol and $v=\left(1 \cdot 10^{-9}\right.$ to $\left.2 \cdot 10^{-9}\right) \mathrm{kg} \cdot \mathrm{s}^{-1}$ for the other compounds studied. A typical vaporisation curve is shown in figure 1.

The value of the calibration constant $(38.9 \pm 0.2) \mathrm{J} \cdot \mathrm{V}^{-1} \cdot \mathrm{s}^{-1}$ was determined from the results obtained for the sublimation enthalpy of naphtalene $\left\{\mathrm{LGC}\right.$ ref $^{\mathrm{a}}$ $\left.0031, x>0.99, \Delta_{\mathrm{sub}} H_{\mathrm{m}}^{0}(72.6 \pm 0.6) \mathrm{kJ} \cdot \mathrm{mol}^{-1}[7]\right\}$. The calibration was checked by measuring the enthalpy of vaporisation for undecane \{Fluka, gas chromatography standard, $\left.x=0.998, \Delta_{\mathrm{vap}} H_{\mathrm{m}}^{0}(56.6 \pm 0.6) \mathrm{kJ} \cdot \mathrm{mol}^{-1}[7]\right\}$. The value obtained was $\Delta_{\mathrm{vap}} H_{\mathrm{m}}^{0}(56.1 \pm 0.3) \mathrm{kJ} \cdot \mathrm{mol}^{-1}(n=6)$.

Meso-2,3-butanediol was the only test compound that is solid at $T=298.15 \mathrm{~K}$. The enthalpy of vaporisation at this temperature was determined from the enthalpy of sublimation at $T=298.15 \mathrm{~K}$ and from the fusion enthalpy at $T=$

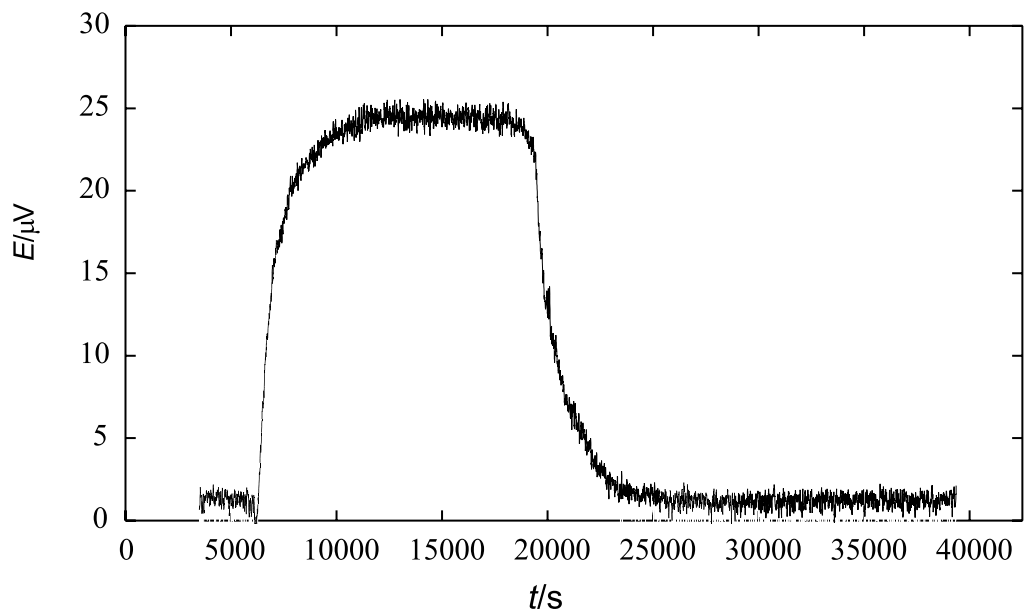

FIGURE 1. Curve of the electromotive force $E$ against time $t$ corresponding to the vaporisation process of a mass $m=13.59 \mathrm{mg}$ of 1,4-butanediol at $T=298.15 \mathrm{~K}$. 
$306.6 \mathrm{~K}$. The enthalpy of fusion was determined by differential scanning calorimetry, with a Perkin Elmer DSC7 calorimeter, according to the procedures given elsewhere [8].

In this work uncertainties are taken to be the standard deviations.

TABLE 2

Enthalpy of vaporisation values $\Delta_{\mathrm{vap}} H_{\mathrm{m}}$ at $T=298.15 \mathrm{~K}$ obtained from different masses $m$ of butanediol isomers

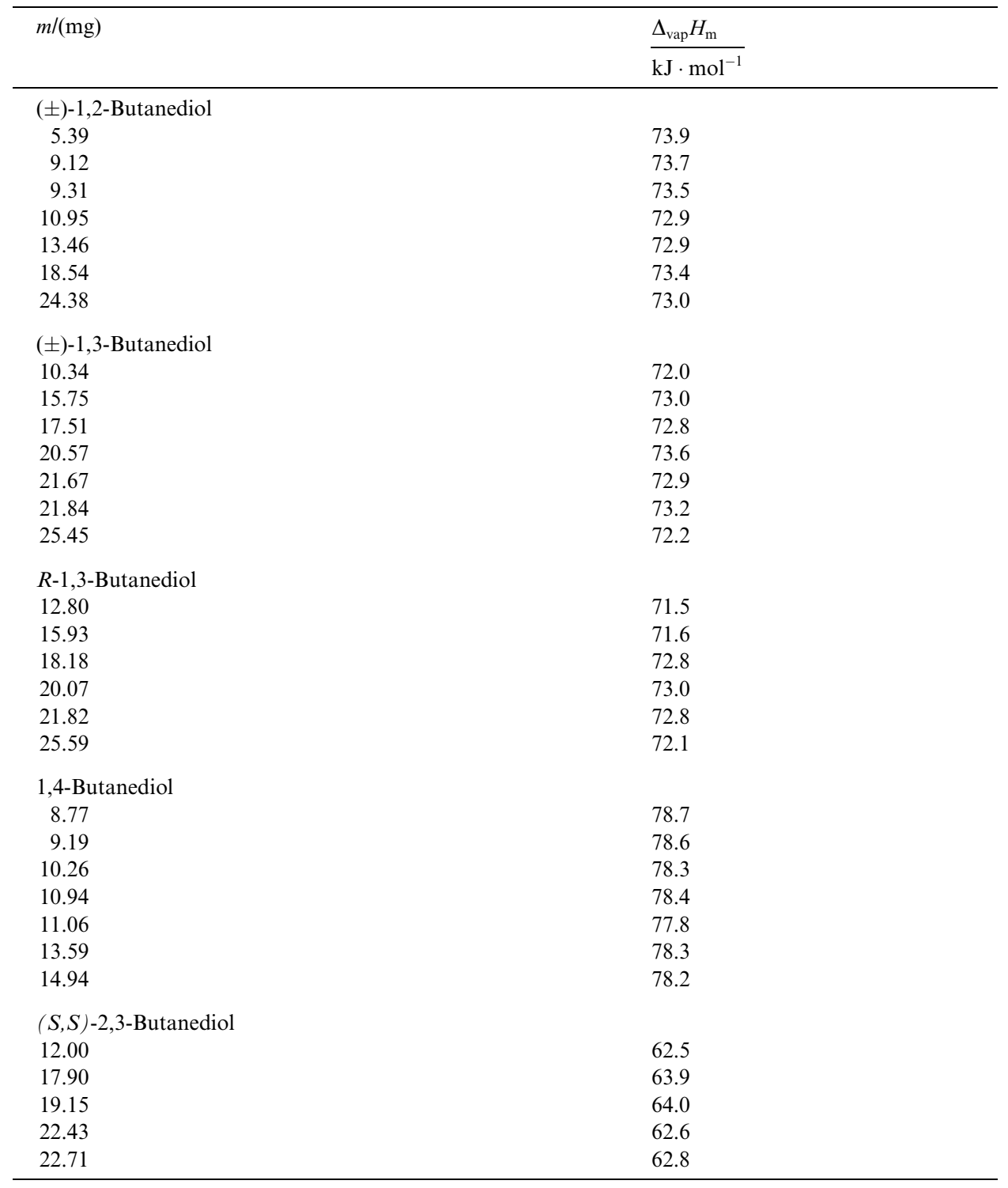




\section{Results}

The values obtained for the enthalpy of vaporisation of butanediol isomers except for meso-2,3-butanediol are presented in table 2.

Table 3 contains the values obtained for the enthalpy of sublimation of meso-2,3butanediol and table 4 those for the enthalpy of fusion of meso-2,3-butanediol. The temperature of fusion of this compound is $T_{\text {fus }}=(306.6 \pm 0.2) \mathrm{K}$ and $\Delta_{\text {fus }} H_{\mathrm{m}}=$ $(10.8 \pm 0.1) \mathrm{kJ} \cdot \mathrm{mol}^{-1}$.

The value of $\Delta_{\mathrm{vap}} H_{\mathrm{m}}^{0}$ for meso-2,3-butanediol at $T=298.15 \mathrm{~K}$ was determined from the experimental results of this substance through the following simple thermodynamic cycle:

$$
\begin{aligned}
\Delta_{\text {vap }} H_{\mathrm{m}}^{0}(T=298.15 \mathrm{~K})= & \Delta_{\text {sub }} H_{\mathrm{m}}^{0}(T=298.15 \mathrm{~K})-\Delta_{\text {fus }} H_{\mathrm{m}}^{0}(T=306.6 \mathrm{~K}) \\
& +\left(C_{p}^{1}-C_{p}^{\mathrm{s}}\right)(306.6 \mathrm{~K}-298.15 \mathrm{~K}),
\end{aligned}
$$

where $C_{p}^{1}$ and $C_{p}^{\mathrm{s}}$ are the heat capacities of the liquid and solid phases, respectively assumed to be constant in the temperature range of interest.

Heat capacity measurements carried out by differential scanning calorimetry on the solid at $T=283.15 \mathrm{~K}$ gave a heat capacity value of $C_{p}^{\mathrm{s}}=(213 \pm 6) \mathrm{J} \cdot \mathrm{mol}^{-1} \cdot \mathrm{K}^{-1}$. From similar measurements made on the undercooled liquid at $T=298.15 \mathrm{~K}$ $C_{p}^{1}=(237 \pm 6) \mathrm{J} \cdot \mathrm{mol}^{-1} \cdot \mathrm{K}^{-1}$ was obtained. From these values we may conclude that

\section{TABLE 3}

Enthalpy of sublimation values $\Delta_{\text {sub }} H_{\mathrm{m}}$ at $T=298.15 \mathrm{~K}$ obtained from different masses $m$ of meso-2,3butanediol

\begin{tabular}{ll}
\hline$m /(\mathrm{mg})$ & $\frac{\Delta_{\text {sub }} H_{\mathrm{m}}}{n}$ \\
\cline { 2 - 2 } $\mathrm{kJ} \cdot \mathrm{mol}^{-1}$ \\
\hline 10.17 & 77.1 \\
10.77 & 77.0 \\
16.22 & 77.4 \\
17.11 & 78.0 \\
21.08 & 77.7 \\
22.00 & 77.1 \\
\hline
\end{tabular}

TABLE 4

Enthalpy of fusion values $\Delta_{\text {fus }} H_{\mathrm{m}}$ and fusion temperature $T_{\text {fus }}$ obtained from different masses $m$ of meso2,3-butanediol

\begin{tabular}{lll}
\hline$m /(\mathrm{mg})$ & $T_{\text {fus }}$ & $\frac{\Delta_{\text {fus }} H_{\mathrm{m}}}{\mathrm{kJ} \cdot \mathrm{mol}^{-1}}$ \\
\cline { 2 - 3 } & $\mathrm{K}$ & 10.8 \\
4.25 & 306.4 & 10.7 \\
3.59 & 306.5 & 10.9 \\
2.38 & 306.7 & 10.9 \\
2.05 & 306.7 & 10.8 \\
\hline .94 & 306.8 & \\
\hline
\end{tabular}


the third term in the above equation gives a negligible contribution to $\Delta_{\text {vap }}$ $H_{\mathrm{m}}^{0}(T=298.15 \mathrm{~K})$.

From the results obtained an estimation of vapour pressure values at $T=298.15 \mathrm{~K}$ can be made, resulting in $p_{\mathrm{v}}=\left\{4,\left(9 \cdot 10^{-1}\right),\left(9 \cdot 10^{-1}\right),\left(8 \cdot 10^{-2}\right)\right.$, 4 and $\left.\left(4 \cdot 10^{1}\right)\right\} \mathrm{Pa}$, respectively for $( \pm)$-1,2-butanediol, $( \pm)$-1,3-butanediol, $R-1,3$ butanediol, 1,4-butanediol, meso-2,3-butanediol and $(S, S)-2,3$-butanediol. For the compounds under study $\Delta_{\mathrm{vap}} H_{\mathrm{m}}=\Delta_{\mathrm{vap}} H_{\mathrm{m}}^{0}$. In table 5 we present the results for $\Delta_{\text {vap }} H_{\mathrm{m}}^{0}$ for the butanediol isomers in this study at $T=298.15 \mathrm{~K}$.

The values obtained in the present work are close to those quoted by Steele [1] and Sabbah [4] whenever comparison is possible, but the differences with the values of other authors are significant.

The results obtained for $\Delta_{\mathrm{vap}} H_{\mathrm{m}}^{0}$ of the isomers were compared using the statistical $t$-test for the difference of the means. The significance levels for the two-sided $t$-test corresponding to the differences between the means are given in table 6.

As one can see from table 6, the probability of a type I error is significant only for the difference between the means of $( \pm)$-1,2-butanediol and $( \pm)$-1,3-butanediol. The difference between the results obtained for $( \pm)$-1,3-butanediol and $(R)$-1,3-butanediol gives a significance level smaller than 0.05 , the limit value often accepted, and all the other systems have $\Delta_{\mathrm{vap}} H_{\mathrm{m}}^{0}$ values significantly different from each other.

TABLE 5

Enthalpy of vaporisation $\Delta_{\mathrm{vap}} H_{\mathrm{m}}^{0}$ at $T=298.15 \mathrm{~K}$ for the compounds studied in this work

\begin{tabular}{ll}
\hline Substance & $\frac{\Delta_{\mathrm{vap}} H_{\mathrm{m}}^{0}}{\mathrm{~kJ} \cdot \mathrm{mol}^{-1}}$ \\
\hline ( \pm -1,2-Butanediol & $73.3 \pm 0.4$ \\
$( \pm)-1,3-B u t a n e d i o l$ & $72.8 \pm 0.6$ \\
$(R)-1,3$-Butanediol & $72.3 \pm 0.7$ \\
1,4-Butanediol & $78.3 \pm 0.3$ \\
$(S, S)$-2,3-Butanediol & $63.2 \pm 0.7$ \\
meso-2,3-Butanediol & $66.6 \pm 0.4$ \\
\hline
\end{tabular}

TABLE 6

Comparison of the mean values of the enthalpies of vaporisation of all pairs of butanediol isomers

\begin{tabular}{lllllll}
\hline & $\begin{array}{l}( \pm)-1,2- \\
\text { Butanediol }\end{array}$ & $\begin{array}{l}( \pm)-1,3- \\
\text { Butanediol }\end{array}$ & $\begin{array}{l}(R)-1,3- \\
\text { Butanediol }\end{array}$ & $\begin{array}{l}1,4- \\
\text { Butanediol }\end{array}$ & $\begin{array}{l}(S, S)-2,3- \\
\text { Butanediol }\end{array}$ & $\begin{array}{l}\text { meso-2,3- } \\
\text { Butanediol }\end{array}$ \\
\hline$( \pm)-1,2-$ Butanediol & 1 & 0.150 & 0.002 & $<0.001$ & $<0.001$ & $<0.001$ \\
$( \pm)-1,3-B u t a n e d i o l$ & & 1 & 0.034 & $<0.001$ & $<0.001$ & $<0.001$ \\
$(R)-1,3-B u t a n e d i o l$ & & & 1 & $<0.001$ & $<0.001$ & $<0.001$ \\
1,4-Butanediol & & & & 1 & $<0.001$ & $<0.001$ \\
$(S, S)-2,3-B u t a n e d i o l$ & & & & & 1 & $<0.001$ \\
meso-2,3-Butanediol & & & & & 1 \\
\hline
\end{tabular}

Significance levels for the two-sided $t$-test applied to all pairs studied in this work. 


\section{Conclusion}

The enthalpy of vaporisation of commercially available butanediol isomers and enantiomers were determined. No data are available for some of the compounds investigated here.

At a confidence level of 99.9 percent the results found for the enthalpies of vaporisation of the isomers differ from each other except for the pairs $( \pm)-1,2-$ and $( \pm)-1$, 3-butanediols, and $( \pm)-1,3$ and $(R)$-1,3-butanediols. For these pairs the confidence levels are 85.0 percent and 96.6 percent, respectively.

Differences between the enthalpies of vaporisation of the isomers cannot be ascribed to structural differences of the compounds in the final or in the initial state, since both contribute to the property. Since for the ideal gas no intermolecular interactions exist, the enthalpy of vaporisation is often related only to the liquid state properties. As the conformation of the isolated molecules of butanediols is determined by intramolecular hydrogen bonds of different strengths [9], such a procedure would be incorrect. In such cases the enthalpy of vaporisation is a valuable tool for probing the liquid structure provided the value of the enthalpy in gas state is known.

\section{References}

[1] W.V. Steele, R.D. Chirico, S.E. Knipmeyer, A. Nguyen, J. Chem. Eng. Data 41 (1996) 1255-1268.

[2] DIPPR, The DIPPR Pure Component Data Compilation, Technical Database Services, Inc., NY, 1997 (version 12.48 for Windows).

[3] P.J. Gardner, K.S. Hussain, J. Chem. Thermodyn. 4 (1972) 819-827.

[4] P. Knaught, R. Sabbah, Bull. Soc. Chim. Fr. 5 (1988) 834-836.

[5] J.B. Peddley, R.D. Naylor, S.P. Kirby, Thermochemical Data of Organic Compounds, second ed., Chapman \& Hall, London, 1986.

[6] R. Sabbah, I. Antipine, M. Coten, L. Davy, Thermochim. Acta 115 (1987) 153-165.

[7] R. Sabbah, A. Xu-Wu, J.S. Chickos, M.L.P. Leitão, M.V. Roux, L.A. Torres, Thermochim. Acta 331 (1999) 93-204.

[8] T.M.R. Maria, F.S. Costa, M.L.P. Leitão, J.S. Redinha, Thermochim. Acta 269/270 (1995) $405-413$.

[9] E. Fishman, T.L. Chen, Spectrochim. Acta 25A (1969) 1231-1242.

WA01/031 